\title{
Research on new transmission network planning considering adjustable comprehensive resources
}

\author{
Zhenghua Chen, Junjie Cao, Shengzhi Lu, Yezhang Cao, Shanshan Zheng, Xiaonan Yang \\ State Grid Jiangsu Electric Power Co., Ltd. Yangzhou Power Supply Company China
}

\begin{abstract}
With the large-scale renewable energy grid integration, the problems of traditional transmission network planning methods, such as high investment, low utilization rate and difficulty in implementation, have gradually emerged. Therefore, in order to improve the level of new energy consumption, effectively improve the operation efficiency of power grid and optimize the investment benefit, this paper proposes a new mode of power grid planning based on adjustable integrated resources. This paper focuses on two key planning methods: new energy confidence capacity assessment methods and load forecasting methods considering demand side resources. Then the paper takes a city-level $220 \mathrm{KV}$ power grid as an example, applies a new power grid planning method to carry out planning, and verifies the effectiveness of the proposed planning model and method.
\end{abstract}

\section{Introduction}

Transmission grid planning is an important part of power system planning. Reasonable and effective transmission grid planning can ensure the healthy development of the power system[1].However, the uncertainty of the power system has also increased due to the increasing proportion of grid-connected renewable energy sources[2]. Therefore, it is particularly important to consider new grid planning with adjustable integrated resources such as renewable energy.

At present, domestic and foreign scholars are also doing a lot of related research on how to carry out new power grid planning. The literature [3] analyzed the challenges and changes brought about by the development of new energy to traditional power transmission technologies, and puts forward the key technologies for the application planning of DC transmission grids. The literature [4] proposed the transmission network planning theory with multi-scene technology, robust optimization technology and collaborative planning technology as the core, and prospected the future transmission network planning methods. In reference [5], HRPTD-20, a transmission network planning and testing system considering transmission and distribution coordination, was constructed under the high proportion of renewable energy access, and the rationality and effectiveness of the test system was verified by comparative analysis. The literature[6] analyzed the important role of load management in power grid planning and concluded that load management was more cost-effective than traditional power grid expansion. The literature[7] proposed a new reliability-oriented mixed integer linear programming method for power networks, and demonstrated that the optimization of the location and capacity of power plants in the power system can reduce the average unsupplied energy cost. In literature[8], a grid planning model for renewable energy access system embedded with unit combination and network structure optimization was established, which provides an important auxiliary decision-making basis for power grid planning.

\section{Traditional power grid planning model}

In recent years, the demand for electricity has been accelerating, and the grid planning and design process has also been continuously improved. When planning and designing traditional power grids, the main purpose is to ensure the optimal situation of the safe and coordinated operation of the system, reduce the system cost in the life cycle as far as possible, and then improve the quality of the whole planning process to meet the peak load and set the planning constraints.

However, with the large-scale grid connection of renewable resources, the continuous development of energy storage technology, and the gradual promotion of demand response measures, there is a new demand for power grid planning. The influence of adjustable comprehensive resources on power transmission network planning is also increasing, which can be divided into the following three aspects: (1) Large-scale renewable energy grid integration increases the random fluctuation of power flow and planning targets in transmission network planning; (2) After the demand response resource mechanism is introduced, the demand response resources that can be saved on the demand side to replace the power transmission and distribution resources are also included in the power planning, so that the resources on both sides of supply and demand can be utilized more efficiently and economically; (3) When planning the power grid,

* Corresponding author: 594842366@qq.com 
reasonable allocation of the location and capacity of energy storage can change the temporal and spatial characteristics of load and renewable energy power, thus changing the transmission performance of the power grid and solving the problem of short-term overload of transmission lines.

There are some following problems in the current traditional power grid planning mode (1) renewable energy is not considered in the power balance planning, and the resulting power balance planning scheme is prone to imbalance in the implementation process, resulting in serious abandonment of wind and light by renewable energy, resulting in resource waste; (2) There are many factors affecting load change, and the fluctuation of power grid load is large. As an important premise and foundation of power grid planning, the accuracy of power load prediction is usually not high; (3) Due to various reasons, the overall urban development plan cannot be well implemented, and the nature of land use in some regions often changes, resulting in uncertainty of load growth, low accuracy of power grid planning and poor adaptability of planning schemes.

Therefore, it is particularly important to take adjustable comprehensive resources into account in power grid planning. By establishing a new optimal dynamic planning mode of power grid based on adjustable comprehensive resources, the operation efficiency of power system can be improved, the absorption of renewable energy can be promoted, the phenomenon of abandoning wind and light can be reduced, and the power grid can operate more safely and stably.

\section{A new transmission network planning mode based on adjustable comprehensive resources}

To build a new type of grid based on adjustable integrated resource planning to build new type of power system, to adapt to the economic and social development planning, and user's growing electricity demand as the basic goal, adjustable integrated resource characteristic is taken into account in planning and its impact, reasonable arrangement of all levels of power grid construction, promote the power grid network frame structure optimization, to achieve efficient operation of the power grid to At the same time, improve the reliability of power supply, reduce power loss as much as possible, and ensure the sustainable development of power grid.Specific ideas are as follows:

(1)Take meeting electricity demand as the fundamental task

Through the continuous improvement of grid reliability and power quality, to maximize the social demand for electricity, and strive to achieve on the premise of realizing social benefits, the development of enterprises, improve the grid, improve the goal of income.

(2) Consider the characteristics and impacts of adjustable comprehensive resources

In view of the "new energy and energy storage" output combination can provide relatively stable power supply, is conducive to the balance of power, the adjustable integrated resources of renewable energy and energy storage resources, should be included in the power balance points area, according to its expected output condition, the methods of confidence capacity assessment, renewable energy and energy storage equivalent to the conventional unit, Incorporate into transmission network planning. In addition, for the demand response resources in the adjustable comprehensive resources, load prediction should be carried out considering the demand response resources, and the load prediction results should be further used as a reference for transmission network planning.

(3) Select a reasonable time section to carry out safety check

Considering the fluctuation and uncertainty of renewable energy output, the nodes with the lowest output stability and minimum output are selected as the time section according to the output curve to carry out power grid security check.

(4) Demand response cost should be considered in the economic evaluation of transmission network planning scheme

The demand response cost should be considered in the economic evaluation of transmission network planning scheme to measure the effectiveness and economy of the new planning mode more effectively.

(5) Promote the coordination between the superior power grid and the subordinate power grid

Subordinate power grid and superior power grid as two ladder units, superior power grid planning as guidance, responsible for macro guidance to subordinate units; As the basis, the subordinate power grid planning is responsible for the execution and implementation of basic tasks.

Among them, when considering the characteristics of adjustable comprehensive resources, the available capacity of renewable energy is determined by using confidence capacity assessment and other methods according to its expected output, and the renewable energy and energy storage are equivalent to conventional units and incorporated into the transmission network planning. For the demand response resources in the adjustable comprehensive resources, load prediction is carried out considering the demand response resources to ensure the accuracy of load prediction, and the load prediction results are further used as a reference for transmission network planning.

\section{Confidence Capacity Evaluation of Renewable Energy}

Among new energy sources, uncertain energy sources such as wind power generation and solar photovoltaic power generation have great fluctuations in their output due to the meteorological environment, resulting in great differences between their actual output and initial installed capacity. New energy capacity of confidence can be summarized new energy influence on abundance degree of power system capacity, not only has the intermittent new energy and conventional unit installed capacity of q can compare at the same level, and make the 
uncontrolled, with volatility and randomness of new energy in traditional power planning analysis and calculation of possible. Therefore, the confidence capacity assessment of renewable energy used in the planning of new power grid is as follows.

\subsection{Evaluate the confidence capacity of a single intermittent power supply}

In this paper, the method used to calculate the confidence capacity assessment is equivalent conventional unit capacity, and the unit with random outage rate is used to replace the renewable energy.

Calculate the confidence capacity of a single intermittent power supply

Assume that the system contains conventional unit capacity $\mathrm{Cr}$ and intermittent power supply to be evaluated. Take wind power as an example, its capacity is $\mathrm{Cw}$, and assume equivalent unit capacity is $\mathrm{Ck}$, which have the same reliability parameters as conventional units. $\mathrm{f}\{\mathrm{C}\}$ represents the reliability index of the system when the total installed unit capacity is $\mathrm{C} ; \mathrm{f}\{\mathrm{Cr}, \mathrm{Cw}\}$ represents the reliability of the system when the conventional unit capacity is $\mathrm{Cr}$ and the wind turbine capacity is $\mathrm{Cw}$; $\mathrm{f}\{\mathrm{Cr}, \mathrm{Ck}\}$ represents the reliability of the system when the conventional unit capacity is $\mathrm{Cr}$ and the equivalent unit capacity is $\mathrm{Ck}$ respectively. If there is:

$$
f\left\{C_{r}, C_{w}\right\}=f\left\{C_{r}, C_{k}\right\}
$$

Then the wind farm confidence capacity $\mathrm{Cv}$ of installed capacity $\mathrm{Cw}$ is defined to be equal to equivalent unit capacity $\mathrm{Ck}$. $\mathrm{f}\{\mathrm{C}\}$ can take different power systems in the calculation of reliability index, such as system load time expected loss, power shortage probability, etc., as an evaluation standard of system reliability.

\subsection{Assess the confidence capacity of the wind- solar-storage combined power generation system}

In the sequential Monte Carlo simulation with time sequence characteristics considered in this paper, if there is a power difference and the available capacity of energy storage equipment cannot meet the difference, the current hour is short of power hours, and the LOLE short of power hours of the system can be obtained after accumulation, which can be expressed as:

$$
f_{\text {LOLE }}=P\left[Y_{d c}(t-1)+P_{h}(t)+P_{m}(t)<P_{L}(t)\right] T
$$

When the wind and landscape storage combined power generation is carried out, the total output power of the wind and landscape storage combined power generation system is set as:

$$
P_{a}=P_{h}+Y_{d c}(t-1)
$$

Depending on the load and unit state, different formulas are used to calculate the EENS of the system. When the load $P_{L}$ is greater than the maximum value $P_{a \max }$ of the combined power generation of scenery storage, there is:

$$
f_{E E N S}=P_{L}-\int_{P_{a \min }}^{P_{a \max }} P_{a} \cdot f_{P_{a}}\left(P_{a}\right) d P_{a}
$$

When $P_{h \min } \leq P_{L} \leq P_{h \max }$,

$$
f_{E E N S}=\int_{P_{a \min }}^{P_{L}}\left(P_{L}-P_{a}\right) \cdot f_{P_{a}}\left(P_{a}\right) d P_{a}
$$

\section{Load forecasting considering demand- side resources}

In order to better compare the economics of traditional power grid planning and new power grid planning that considers adjustable integrated resources, on the basis of traditional load forecasting, the power saving effect of energy-efficient demand-side resources and the peakshaving of load-type demand-side resources are superimposed. Grain filling effect, realizing regional maximum load forecasting considering demand-side resources.

\subsection{Annual electricity load forecast}

When the demand-side resources are not considered, the forecast of the annual electricity load. As shown in formulas (7) and (8):

$$
\begin{aligned}
q_{1}^{0}=q_{2} \cdot(1+\varphi)^{T} & \\
& P_{1}^{0}=q_{2}^{0} / \beta_{0} \cdot H
\end{aligned}
$$

In the formula, it represents the total power consumption in the target year without considering the demand side resources, MWh; is the initial annual power consumption, $\mathrm{MWh}$; is the average annual growth rate of power consumption; $\mathrm{T}$ represents the forecast period, year; represents The maximum load in the target year without considering the demand side resources, MW; is the average load rate; $\mathrm{H}$ represents the total effective time in the forecast period, in hours.

\subsection{Load forecast correction}

(1) The maximum load forecast revision considering the energy-saving effect of energy-efficient resources Assuming that the type of energy efficiency resource owned by this type of user is I, the calculation method of the energy saving that can be achieved in the calculation area is as follows:

$$
q_{n, e}=q_{n, 1}^{0}-\Delta q_{n, e}, n \in N
$$

Among them, represents the power saving brought by energy efficiency resources of the nth user in the area, $\mathrm{MWh}$; it is the total power consumption after the effect of the energy efficiency resources in the coverage area of the substation.

(2) The maximum load forecast correction considering the effect of peak shaving and valley filling of load resources When this type of user responds to multiple load resources, the superimposed effect is as follows:

$$
\begin{gathered}
\Delta P_{n}^{r}=\sum_{j}^{J} \alpha_{j} \cdot \Delta P_{n, j}^{r} \quad n \in N, j \in \Omega_{J} \\
P_{n}^{D}=P_{n}^{e}-\Delta P_{n}^{r}, n \in N
\end{gathered}
$$

Among them, represents the total number of load resources owned by this type of user; represents the probability of this type of user responding to the load 
resource, which is related to the resource type. This parameter can be counted by monitoring the response of a user to the load resource in real time; represents coverage The maximum load, MW, of the nth type of user in the area after being affected by all demand-side resources.

(3) Regional comprehensive maximum load forecast revision considering the role of multiple demand-side resources

Since the types and numbers of users are different, the time node when the maximum load occurs when calculating the comprehensive maximum load in the coverage area may not be exactly the same. After the load simultaneous rate is introduced and adjusted, it can be obtained:

$$
\begin{gathered}
P^{D}=\alpha_{n}\left(\sum_{n=1}^{N} P_{n}^{r}\right), n \in N \\
P_{\max }^{D}=\alpha_{n} P^{D} \\
\Delta S=R\left(P_{1}^{0}-P_{\max }^{D}\right)
\end{gathered}
$$

Among them, represents the maximum load of multiple types of users in the coverage area of the substation under the comprehensive action of demand-side resources, MW; represents the simultaneous load rate, which is used to adjust the maximum load between different types of power users; $\mathrm{N}$ is the total number of user types; is the area The comprehensive maximum load is as follows, MW; represents the substation capacity that can be avoided or postponed after taking into account the resources on the demand side, MVA; $\mathrm{R}$ represents the capacity-to-load ratio.

\section{Example analysis}

\subsection{Basic data}

This paper uses a municipal $220 \mathrm{kV}$ power grid as a pilot, and uses the scale and output of new energy and energy storage as basic data. The planning scenario is set on the basis of the load and power level of the original grid plan, and the demand side response is considered. The impact of resources on the grid load and the impact of new energy power stations and energy storage power stations on power output. The settings of the five scenarios are shown in Table 1:

Table 1 Scenario setting

\begin{tabular}{|c|c|c|}
\hline & $\begin{array}{c}\text { Energy storage } \\
\text { configuration } \\
\text { ratio }\end{array}$ & $\begin{array}{c}\text { Demand-side } \\
\text { resources ratio }\end{array}$ \\
\hline Scenario 1 & $10 \%$ & $10 \%$ \\
\hline Scenario 2 & $5 \%$ & $10 \%$ \\
\hline Scenario 3 & $15 \%$ & $10 \%$ \\
\hline Scenario 4 & $10 \%$ & $12.5 \%$ \\
\hline Scenario 5 & $10 \%$ & $7.5 \%$ \\
\hline
\end{tabular}

Carry out confidence capacity assessment and load forecast for different scenarios according to 3.1 and 3.2.

\subsection{Planning scheme analysis}

Perform $500 \mathrm{kV}$ power balance analysis and $220 \mathrm{kV}$ capacity-load ratio analysis for municipal power grids. According to the $500 \mathrm{kV}$ and $220 \mathrm{kV}$ substation capacity requirements under different scenarios, check and optimize the necessity and construction sequence of the original power grid project to form 5 different scenarios of power grids List of planned capacity items. The original power grid planning and the number of capacity projects under the five scenarios and the demand for substation capacity are shown in Table 2,and the planned capacity project arrangements for the power grid under each scenario are shown in Table 3.

Table 2 Number of power grid planning projects under different scenarios

\begin{tabular}{|c|c|c|c|}
\hline & $\begin{array}{c}\text { Number of } \\
\text { items }\end{array}$ & $500 \mathrm{kV}$ & $220 \mathrm{kV}$ \\
\hline Original plan & 14 & 3 & 11 \\
\hline Scenario 1 & 6 & 1 & 5 \\
\hline Scenario 2 & 6 & 1 & 5 \\
\hline Scenario 3 & 5 & 0 & 5 \\
\hline Scenario 4 & 2 & 0 & 2 \\
\hline Scenario 5 & 7 & 1 & 6 \\
\hline
\end{tabular}

Table 3 Capacity of power grid planning projects under different scenarios

\begin{tabular}{|c|c|c|c|}
\hline & $\begin{array}{c}\text { Substation } \\
\text { capacity }\end{array}$ & $500 \mathrm{kV}$ & $220 \mathrm{kV}$ \\
\hline $\begin{array}{c}\text { Original } \\
\text { plan }\end{array}$ & 5230 & 3250 & 1980 \\
\hline Scenario 1 & 1090 & 250 & 840 \\
\hline Scenario 2 & 1150 & 250 & 900 \\
\hline Scenario 3 & 840 & & 840 \\
\hline Scenario 4 & 360 & & 360 \\
\hline Scenario 5 & 1330 & 250 & 1080 \\
\hline
\end{tabular}

It can be seen from the table that the number and capacity of power grid planning under the five scenarios have been significantly reduced. The largest number of planned projects is 7 in scenario 5, the least is 2 in scenario 4, and the 14 in the original planning report. In comparison, the number has more than doubled. Among them, the capacity of the power grid planning project in scenario 5 is reduced from the original plan of 5230 to 1330 , which is a reduction of 3900; the capacity of the power grid planning project in scenario 4 is reduced to 360 , which is a reduction of 4870 . In addition, the capacity of Scenario 1 grid planning project is reduced by 4140 compared with the original plan, Scenario 2 is reduced by 4080, and Scenario 2 is reduced by 4390 .

\subsection{Evaluation of planning schemes}

The economics of power grid planning schemes under 5 different scenarios are evaluated. The operating period is 
30 (years), the fixed asset conversion rate is $95 \%$, the grid operation and maintenance rate is $2 \%$, and the load reduction compensation price is 10 (yuan). $/ \mathrm{kw}$ ), the discount rate is $8 \%$, and the annual adjustable resource utilization cost mainly considers the demand response cost. The economic benefits of each scenario are calculated and compared using the total investment during the planning period and the life cycle cost indicators. The results are shown in Table 4:

Table 4 Economic Comparison of Each Scenario

\begin{tabular}{|c|c|c|c|c|}
\hline \multicolumn{1}{|c|}{ Plannin } \\
g \\
$\begin{array}{c}\text { scenari } \\
\text { o }\end{array}$ & $\begin{array}{c}\text { New load } \\
\text { during } \\
\text { planning } \\
\text { period } \\
\text { (MW.h } \\
\text { ) }\end{array}$ & $\begin{array}{c}\text { Constructi } \\
\text { on } \\
\text { investment } \\
\text { investme } \\
\text { nt to } \\
\text { increase } \\
\text { supply } \\
\text { load } \\
\text { (MW/h/ } \\
\text { yuan) }\end{array}$ & $\begin{array}{c}\text { Total life } \\
\text { cycle } \\
\text { cost }\end{array}$ \\
\hline $\begin{array}{c}\text { Origina } \\
\text { l plan }\end{array}$ & 1989 & 1479.41 & 134 & $\begin{array}{c}1762.259 \\
1\end{array}$ \\
\hline $\begin{array}{c}\text { Scenari } \\
\text { o 1 }\end{array}$ & 1794 & 400.41 & 448 & 531.2785 \\
\hline $\begin{array}{c}\text { Scenari } \\
\text { o 2 }\end{array}$ & 1794 & 435.41 & 412 & 572.9701 \\
\hline $\begin{array}{c}\text { Scenari } \\
\text { o 3 }\end{array}$ & 1794 & 359.69 & 499 & 482.7732 \\
\hline $\begin{array}{c}\text { Scenari } \\
\text { o 4 }\end{array}$ & 1745 & 199.69 & 874 & 317.1267 \\
\hline $\begin{array}{c}\text { Scenari } \\
\text { o 5 }\end{array}$ & 1843 & 455.41 & 405 & 584.3219 \\
\hline
\end{tabular}

Comparing the total cost of the five set scenarios in the table with the original planning report during the planning period, it can be found that the total cost of the five scenarios considering comprehensive adjustable resources during the planning period is lower. Therefore, the comprehensive adjustable resources are included in the transmission grid planning. It can reduce the grid investment cost during the planning period to a certain extent. In addition, the investment efficiency of each planning scenario considering adjustable comprehensive resources has been significantly improved. In terms of increasing the supply load of unit investment, the most obvious improvement in investment efficiency is in Scenario 4, followed by Scenarios 3 and 1, and Scenario 5 is the worst.

In summary, the planning idea of considering comprehensive adjustable resources is conducive to improving the economics of power grid operation. Scenario 4 with the highest demand response participation rate is the most economical, which can bring higher investment efficiency and greater economic benefits to power grid companies.

\section{Conclusion}

This paper proposes a new power grid planning model based on adjustable integrated resources, and takes a municipal power grid as an example to apply new grid planning methods to carry out planning. The planning results show that adjustable integrated resources such as renewable energy, energy storage, and demand response are in place. Power grid planning has a certain substitution effect on traditional power. Among them, the available potential of demand response resources and the impact of incorporating them into power grid planning are greater. Therefore, this article puts forward the following related suggestions for the planning of the transmission grid: (1) Focus on the alternative role of adjustable resources in grid planning, and use it as an alternative resource on the power generation side for comprehensive planning; (2) In the future, power transmission In the process of network planning, the incentive space of the power market mechanism should be tapped, and the incentive role of the power market should be considered in the power grid planning; (3) The power system planning problem based on big data can be analyzed and processed by the collected power big data to reduce the impact Dependence on the physical model.

\section{Acknowledgements}

This work was financially supported by State Grid Jiangsu Electric Power Co., Ltd. Yangzhou Power Supply Branch Management Consulting Project "Research on Transmission Grid Planning Based on Adjustable Integrated Resources".

\section{References}

1. Liu Shuai, Kong Liang, Liu Zifa, Li Yuwen, Chen Yixuan. Transmission grid planning method based on deep reinforcement learning [J]. Electric Power Construction, 2021, 42(07): 101-109.

2. Liu Dundun, Cheng Haozhong, Liu Jia, Zeng Pingliang, Zhang Jianping, Lu Jianzhong. Overview and prospects for robust planning of transmission grids[J]. Power System Technology, 2019, 43(01): 135-143.

3. Lu Jingjing, He Zhiyuan, Zhao Chengyong, et al. Key technologies and prospects for HVDC grid planning $[\mathrm{J}]$. Automation of Electric Power Systems, 2019, 43(2): 182-191.

4. Liu Lu, Cheng Haozhong, Wu Yaowu, et al. Research progress and prospects of transmission grid planning methods for high proportion of renewable energy[J]. Automation of Electric Power Systems, 2021, 45(13): 176-183.

5. Li Aowei, Liu Lu, Cheng Haozhong, et al. Transmission grid planning and testing system considering transmission and distribution coordination under high proportion of renewable energy access[J]. Automation of Electric Power Systems, 2021, 45(11): 19-27.

6. Wintzek Patrick et al. Application and Evaluation of Load Management Systems in Urban Low-Voltage Grid Planning[J]. World Electric Vehicle Journal, 2021, 12(3): 91-91. 
7. Ghayoor Fatemeh and Ghannadpour Seyed Farid and Imani Din Mohammad. Bi-objective robust optimization for reliability-oriented power network planning by considering distributed generation effects: A case study in Iran[J]. Sustainable Energy, Grids and Networks, 2021, 26(prepublish): 100455.

8. Wang Weichen, Zhang Tianyu, Xuan Wenbo, etc. Power grid planning method considering unit commitment and network structure optimization[J]. Proceedings of the CSU-EPSA, 2021, 33(2): 108-115. 